\title{
Total Synthesis of Cardamom Peroxide
}

Synthesis of Natural

Products and

Potential Drugs

\section{Key words}

cardamom peroxide

antimalarial

biosynthetic

manganese

hydroperoxidation

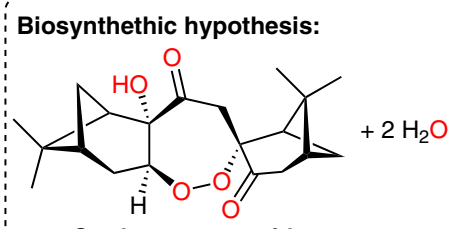

Cardamom peroxide

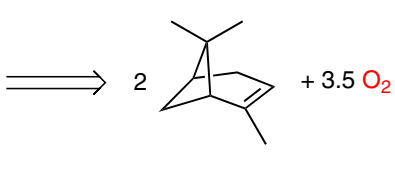
$\alpha$-pinene
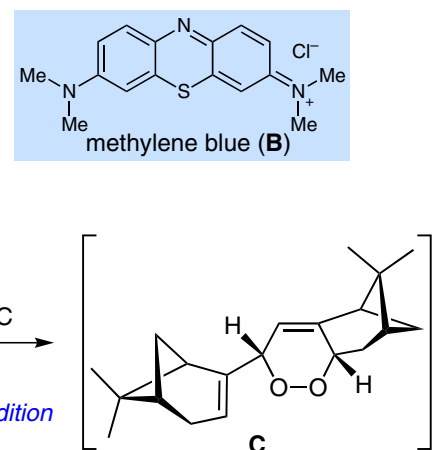

A

$\mathrm{O}_{2}[4+2]$ cycloaddition

(-)-myrtena

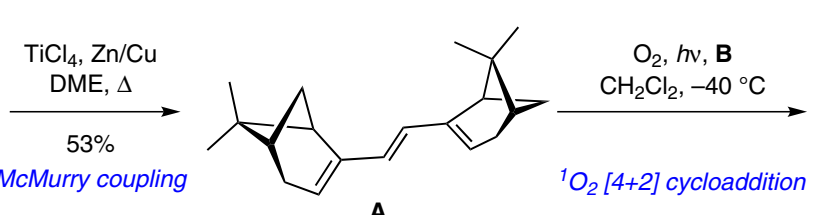

Kornblum-DeLaMare $56 \%$ rearrangement (+12\% of E)

$\mathrm{O}_{2}$

$\mathrm{Mn}(\mathrm{dpm})_{3}(20 \mathrm{~mol} \%)$ $t-\mathrm{BuOOH}$ (1.5 equiv)

$\mathrm{PhSiH}_{3}$ (2.5 equiv)

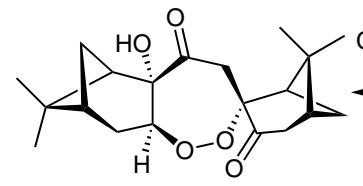

Cardamom peroxide $\mathrm{CH}_{2} \mathrm{Cl}_{2}-i$ - $\mathrm{PrOH}(6.5: 1)$

Significance: In the wake of the success of artemisinin for the treatment of chloroquine-resistant malaria, enormous interest has been placed in naturally occurring organic peroxides as potential leads for medicinal chemistry. Cardamom peroxide, a diterpenoid containing a seven-membered cyclic peroxide, was isolated from Siam cardamom in 1995 by Clardy and co-workers and, although it has been shown to be highly active against Plasmodium falciparum, has only now succumbed to total synthesis. Hu and Maimone identified a non-obvious symmetry and hypothesized that cardamom peroxide could be stitched together by two monoterpenes and molecular oxygen. Brilliantly executing this plan, they were able to synthesize the target compound in only four steps from (-)-myrtenal.
Comment: Following the biosynthetic hypothesis, the authors settled on (-)-myrtenal as the monoterpenoid starting material. McMurry coupling led to triene $\mathbf{A}$ which underwent a [4+2] cycloaddition with singlet oxygen. The resulting peroxide was not isolated but treated with $\mathrm{DBU}$, leading to a Kornblum-DeLaMare rearrangement to give dienone D. Oxidation to the diketone $\mathbf{E}$ then set the stage for the crucial oxidation reaction. Extensive experimentation identified a manganese-catalyzed radical hydroperoxidation which leads to regioselective functionalization of the doubly activated olefin. Following 7-endo cyclization, trapping with oxygen gave the corresponding $\alpha$-hydroperoxyketone which was reduced using $\mathrm{Ph}_{3} \mathrm{P}$ to afford cardamom peroxide. Using this highly efficient strategy, the natural product was constructed in $18 \%$ yield over four steps. 